\title{
ANALISA PERHITUNGAN, DAN PERFORMA POMPA SENTRIFUGAL ITEM A 124 J PADA UNIT AMONIA PT XY
}

\author{
Geri Permana1,a, Rizal Hanifi,,b, Kardiman ${ }^{3, c}$ \\ ${ }^{123}$ Program Studi Teknik Mesin, Fakultas Teknik, Universitas Singaperbangsa \\ Karawang
}

ageripermana1999@gmail.com, brizalhanifi@ft.unsika.ac.id, ckardiman@ft.unsika.ac.id

\begin{abstract}
Abstrak
Sektor industri merupakan salah satu tiang penyangga perekonomian Negara Repulik Indonesia yang sangat vital. Hal ini karena sektor industri selain sebagai penghasil devisa juga memiliki suatu fungsi sosial yaitu sebagai penyerap tenaga kerja dan sebagai pendukung sektor-sektor lain. Kekayaan alam dan keuntungan geografis Negara Republik Indonesia adalah salah satu alasan mengapa sektor industri merupakan suatu prospek yang sangat baik. Pompa adalah peralatan pendukung mekanis yang digunakan PT. XY untuk memindahkan fluida incompressible dari torrent. Salah satu jenis pompa yang banyak dijumpai dalam bidang industri ialah pompa sentrifugal, pompa sentrufugal ini digerakan oleh penggerak mula dimana pada pengoprasiannya mempunyai prinsip putaran impeller sebagai elemen pemindah fluida. Turunnya performansi pada pompa secara tiba-tiba dalam operasi sering mengakibatkan suatu permasalahan yang serius dan dapat mempengaruhi pada kinerja sistem secara keseluruhan. Metode yang dipakai pada penelitian ini ialah terjun langsung kelapangan dengan mengamati kinerja pompa di PT. XY. Dari hasil analisa sesuai dengan spesifikasi Pompa A 124 J didapatkan nilai Debit (Q) sebesar 77,9 m3 /h dan nilai Head sebesar 79,5m, sedangkan pada analisa perhitungan aktual didapatkan nilai Head sebesar 55,36 m, pada perbandingan tersebut dapat diketahui berapa besarnya selisih antara Head teoritis dengan Head aktual, adanya selisih ini di karenakan pada pengoperasiannya hanya di butuhkan Head sebesar 55,36 m dengan rata-rata 77,9 m3 /h.
\end{abstract}

Kata kunci : pompa setrifugal, performa, spesifikasi

\begin{abstract}
The industrial sector is one of the pillars of indonesia's vital economy. This is because the industrial sector other than foreign exchange earners also has a social function, namely as a labor absorber and as a supporter of other sectors. The natural wealth and geographical advantages of the Republic of Indonesia are one of the reasons why the industrial sector is an excellent prospect.Pumps are mechanical support equipment used by PT. XY to remove incompressible fluid from the torrent. One type of pump that is often found in the industrial sector is a centrifugal pump, this centrifugal pump is driven by a prime mover which in its operation has the principle of impeller rotation as a fluid transfer element. A sudden drop in pump performance in operation often results in a serious problem and can affect the overall system performance. The method used in this study is to go directly to the field by observing the performance of the pump at PT. $X Y$. From the results of the analysis according to the specifications of Pump A $124 \mathrm{~J}$, the discharge value $(Q)$ is $77.9 \mathrm{~m} 3 / \mathrm{h}$ and the Head value is $79.5 \mathrm{~m}$, while the actual calculation analysis shows the Head value of $55.36 \mathrm{~m}$, in this comparison it can be seen how big is the difference between the theoretical Head and the actual Head, this
\end{abstract}


difference is because in operation it only requires a Head of $55.36 \mathrm{~m}$ with an average of $77.9 \mathrm{~m} 3 / \mathrm{h}$.

Key words : centrifugal pump, performance, specifications

\section{PENDAHULUAN}

Sebagai perusahaan yang bergerak dalan bidang penyediaan pupuk di indonesia, PT XY membutuhkan mesin dan perawatan yang beroprasi dalam kondisi baik, agar dapat mencapai produksi [1]. Pompa ialah salah satu alat pendukung dalam proses produksi yang bergerak dalam hal pendistribusian cairan terutama air[2] .

Pompa adalah suatu alat yang berfungsi untuk memindahkan fluida dari satu tempat ke tempat yang lainnya secara kontinyu dengan menggunakan suatu media perpipaan melalui cara menambahkan energi pada fluida yang dipindahkan [3]. Pompa Sentrifugal ini memiliki peranan yang sangat penting karena pompa ini banyak digunakan, dimana pada pompa sentrifugal ini memperbaharui tenaga mekanik sebagai tenaga fluida melalui gaya sentrifugal yang terdiri dari sebuah sudu impeler dan motor penggerak lalu fluida di salurkan ke saluran buang dengan memakai tekanan..(tenaga kinetis sebagian fluida diubah sebagai tenaga tekanan) dengan memakai impeller yang berputar pada casing. Casing tadi dihubungkan dengan saluran hisap (suction) dan saluran tekan (discharge), supaya menjaga agar di dalam casing selalu terisi menggunakan cairan akibatnya saluran hisap harus dilengkapi dengan katup kaki (foot valve) [4].

Beberapa keutamaan dari Pompa Sentrifugal ialah: harga yang relatif murah, kontruksi pada pompa sederhana, gampang dalam pemasangan dan juga perawatan, tinggi dan kapasitas tekan yang tinggi, ketahanan yang tinggi yaitu tahan terhadap operasi jangka panjang [5]
Supaya pompa sentrifugal yang dipakai dalam suatu instalasi eksekutif bisa memenuhi kebutuhan yang sesuai dengan apa yang diharapkan, maka perlu dilakukan pengujian terhadap spesifikasi pompa yang dipakai, lantaran masih ada kemungkinan spesifikasi pompa tidak sesuai dengan kenyataan di lapangan, akibatnya pompa gagal dipergunakan [6]

Permasalahan yang dapat terjadi pada pompa sentrifugal ialah turunnya Performance pada pompa , yang berhubungan dengan penurunan debit, penurunan tekanan, dan vibrasi. Jika pompa tidak dilakukan preventive maintenance maka permasalahan akan banyak terjadi [7].

\section{METODE PENELITIAN}

\section{a. Diagram Alir}

Langkah - langkah yang diambil dalam realisasi penelitian ini adalah seperti terlihat pada gambar 1. di bawah ini :

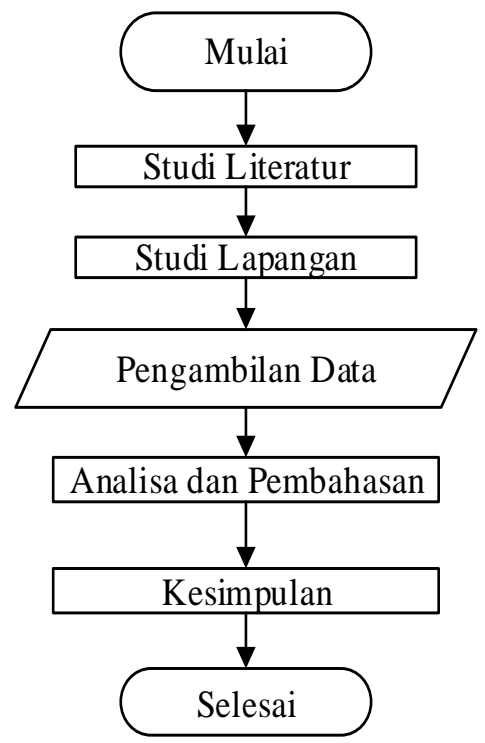

Gambar 1. Diagram Alir penelitian 
b. Pengambilan Data

Data teknis pompa

Manufacture : Ebara Corporation

Type : Centrifugal Pump

Service : Cold Amonia Pump

Liquid : Amonia

No. Item : A $124 \mathrm{~J}$

Power : $21,4 \mathrm{kw}$

ITP $\quad: 73,8 \mathrm{~kg} / \mathrm{cm}^{2}$

Capacity $\quad: 67,9+10 \mathrm{~m}^{3} / \mathrm{h}$

Head : $79,5 \mathrm{~m}$

Press. Suc : :0,341 Kg/cm ${ }^{2}$

Putaran : $2940 \mathrm{rpm}$

NPSHr $\quad: 3,9 m$

Max temp. $: 40^{\circ} \mathrm{C}$

BHP(rated) : $30,5 \mathrm{kw}$

Efisiensi pompa: $72.5 \%$

$\eta$ motor $\quad: 0,71$

Data teknis motor

Manufacture

Jenis : TEFC

Daya : $30 \mathrm{kw}$

Voltage : 380

Frekuensi : $50 \mathrm{~Hz}$

Putaran : $3000 \mathrm{rpm}$

Ampere : $50 \mathrm{~A}$

Phase : 1

Weight : 40

Amp : 54

Volume : 220

Roles : : 2

c. Metode Analisis

Komponen yang harus diperhatikan dalam pengambilan data adalah pompa air. Alat ukur yang digunakan untuk memperoleh data adalah[8]:

1. Presure Gauge $=$ alat ukur tekanan

2. Flowmeter $=$ Alat ukur debit $(\mathrm{Q})$

\section{d. Spesifikasi Pompa}

Data-data yang terdapat dilapangan berupa spesiflkasi pompa yang disajikan sebagai berikut:

- Diameter pipa 6 inch $=0,152 \mathrm{~m}$

- Kapasitas aliran $=77,9 \mathrm{~m}^{3} / \mathrm{h}=$ $0,0215 \mathrm{~m}^{3} / \mathrm{s}$

Luas penampang pipa $1(\mathrm{~m} 2)=$ $0,01813 \mathrm{~m}^{2}$
- Luas penampang pipa $2(\mathrm{~m} 2)=$ $0,0081 \mathrm{~m}^{2}$

- Densitas : $980,4 \mathrm{~kg} / \mathrm{m}^{3}$

- Viscositas : 0,73 x $10^{3}\left(\mathrm{~m}^{2} / \mathrm{s}\right)$

- Panjang pipa $1=6 \mathrm{~m}$

- Panjang pipa $=5 \mathrm{~m}$

- Diameter pipa $=4$ inci $=0,1016 \mathrm{~m}$

- Kapasitas aliran $=77,9 \mathrm{~m}^{3} / \mathrm{h}=$ $0,0215 \mathrm{~m}^{3}$

\section{HASIL PEMBAHASAN}

a. Perhitungan bagian suction pompa

1. Kecepatan Aliran

$\mathrm{V}=\frac{Q}{A}$

$\mathrm{V}=\frac{0,0215}{0,01813}$

$\mathrm{V}=1,187 \mathrm{~m} / \mathrm{s}$

2. Jenis Aliran

$\operatorname{Re}=\frac{1,187 \times 0,152}{0,73 \times 10^{3}}$

$\operatorname{Re}=247,15$ (laminer)

3. Kerugian Pada Suction

a. Kerugian Mayor

$$
\begin{aligned}
& h_{l M}=f \cdot \frac{i}{d} \cdot \frac{v^{2}}{2 g} \\
& h_{I M}=0,25 \cdot \frac{6 m}{0,152} \cdot \frac{1,187^{2}}{2 \times 9,81} \\
& h_{I M}=6,80 \mathrm{~m}
\end{aligned}
$$

b. Kerugian Minor

$$
\begin{aligned}
& h_{l m}=n \cdot k \cdot \frac{v^{2}}{2 g} \\
& h_{l m}=3.0,25 \cdot \frac{1,187^{2}}{2 \times 9,81} \\
& h_{l m}=5,1 \mathrm{~m}
\end{aligned}
$$

- Kerugian karena adanya tee line 1 buah

$$
\begin{aligned}
& h_{l m}=n \cdot k \cdot \frac{v^{2}}{2 g} \\
& h_{l m}=1.0,25 \cdot \frac{1,187^{2}}{2 \times 9,81} \\
& h_{l m}=1,72 \mathrm{~m}
\end{aligned}
$$

- kerugian karena valve 1 buah

$$
\begin{aligned}
& h_{l m}=n \cdot k \cdot \frac{v^{2}}{2 g} \\
& h_{l m}=1.0,25 \cdot \frac{1,187^{2}}{2 \times 9,81}
\end{aligned}
$$


$h_{l m}=1,72 \mathrm{~m}$

Jadi kerugian $h_{l m}$ total $=8,5 \mathrm{~m}$

b. Perhitungan di bagian Discharge Pompa

1. Kecepatan aliran

$$
\begin{aligned}
& \mathrm{V}=\frac{Q}{A} \\
& \mathrm{~V}=\frac{0,0215}{0,0081} \\
& \mathrm{~V}=2,65 \mathrm{~m} / \mathrm{s}
\end{aligned}
$$

2. Jenis aliran

$$
\begin{aligned}
\operatorname{Re} & =\frac{V \cdot D}{v} \\
\operatorname{Re} & =\frac{2,65 \times 0,1016}{0.73 \times 10^{3}} \\
\operatorname{Re} & =368,49 \text { (laminer) }
\end{aligned}
$$

3. Kerugian pada discharge

a. Kerugian Mayor

$$
\begin{aligned}
& h_{l M}=f \cdot \frac{i}{d} \cdot \frac{v^{2}}{2 g} \\
& h_{l m}=0,17 \cdot \frac{5 m}{0,1016} \cdot \frac{2,65^{2}}{2 \times 9,81} \\
& h_{l m}=28.8 \mathrm{~m}
\end{aligned}
$$

b. Kerugian Minor

$$
h_{l m}=n \cdot k \cdot \frac{v^{2}}{2 g}
$$

- Kerugian karena adanya elbow 3 buah

$$
\begin{aligned}
& h_{l m}=n \cdot k \cdot \frac{v^{2}}{2 g} \\
& h_{l m}=1 \cdot 0,17 \cdot \frac{2,65^{2}}{2 \times 9,81} \\
& h_{l m}=17,5 \mathrm{~m}
\end{aligned}
$$

- Kerugian karena adanya valve 1 buah

$$
\begin{aligned}
& h_{l m}=n \cdot k \cdot \frac{v^{2}}{2 g} \\
& h_{l m}=1 \cdot 0,17 \cdot \frac{2,65^{2}}{2 \times 9,81} \\
& h_{l m}=5,8 \mathrm{~m}
\end{aligned}
$$

Jadi $h_{l m}$ total $=23,3 \mathrm{~m}$

c. Perhitungan Head Aktual Pompa
$\mathrm{H}=\frac{p d-p s}{y}$

$\mathrm{H}=\frac{5,77 \mathrm{~kg} / \mathrm{cm} 2-0,34 \mathrm{~kg} / \mathrm{cm} 2}{y}$

$\mathrm{H}=\frac{565843,7 \mathrm{n} / \mathrm{m}^{2}-33342,61 \mathrm{n} / \mathrm{m}^{2}}{980,4 \times 9,81}$

$\mathrm{H}=55,36 \mathrm{~m}$

d. Daya Hidrolis Water Horsepower (WHP) Desain

$\mathrm{WHP}=\gamma x H x \mathrm{Q}$

$\mathrm{WHP}=980,4 \times 79,5 \times 0,0215$

$W H P=1675,74 j / s$

e. Daya Hidrolis Water Horsepower (WHP) Aktual

Dimana debit $=77,9 \mathrm{~m} 3 / \mathrm{h}=0,0215$ $\mathrm{m} 3 / \mathrm{s}$

$\mathrm{WHP}=\gamma x H x Q$

$\mathrm{WHP}=980,4 \times 55,36 \times 0,0215$

$W H P=1166,91 \mathrm{j} / \mathrm{s}$

f. Daya Poros Brakr Horsepower (BHP) Aktual

$B H P=\sqrt{3} .380 .50 \quad 0,71$

$B H P=2336,3 j / s$

g. Efisiensi Pompa Aktual

$\eta_{\text {Pompa }}=\frac{\mathrm{WHP}}{\mathrm{BHP}} \cdot 100 \%$

$\eta_{\text {Pompa }}=\frac{1166,91}{2336,3} \cdot 100 \%$

$\eta_{\text {Pompa }}=49,94 \%$

\section{h. Pembahasan}

Sesuai dengan spesifikasi Pompa A 124 J didapatkan nilai Debit (Q) sebesar 77,9 $\mathrm{m} 3$ /h dan nilai Head sebesar 79,5 $\mathrm{m}$, sedangkan pada analisa perhitungan aktual didapatkan nilai Head sebesar $55,36 \mathrm{~m}$, pada perbandingan tersebut dapat diketahui berapa besarnya selisih antara Head teoritis dengan Head aktual, adanya selisih ini di karenakan adanya beberapa penyebabnya antara lain : 
-Dalam pengoperasiannya Pompa hanya membutuhkan head rata-rata sebesar 55,36 m, dengan kata lain head rata-rata sebesar 55,36 pompa sudah bekerja secara maksimal tanpa membutuhkan head maksimal dari pompa.

- Begitu juga dengan pengoperasiannya hanya di butuhkan debit rata-rata 77,9 $\mathrm{m} 3 / \mathrm{h}$, dengan kata lain debit rata-rata $77,9 \mathrm{~m} 3 / \mathrm{h}$ pompa sudah beroperasi secara maksimal tanpa membutuhkan debit maksimal dari pompa.

- Kerugian akibat adanya gesekan, elbow,valve,dan tee line pada bagian suction adalah sebesar 8,5 $\mathrm{m}$ sedangkan pada bagian discharge adalah sebesar 23,3 m.

- Kecepatan aliran pada Suction adalah $1,187 \mathrm{~m} / \mathrm{s}$, dan Kecpatan aliran pada Discharge adalah 2,65 m/s.

\section{KESIMPULAN}

Pompa mengubah energi mekanik motor menjadi energi aliran fluida. Energi yang di terima oleh fluida digunakan untuk memindahkan fluida dari satu tempat ke tempat lainnya.Dari hasil analisa sesuai dengan spesifikasi Pompa A $124 \mathrm{~J}$ didapatkan nilai Debit (Q) sebesar $77,9 \mathrm{~m}^{3} / \mathrm{h}$ dan nilai Head sebesar 79,5m, sedangkan pada analisa perhitungan aktual didapatkan nilai Head sebesar 55,36 m, dari perbandingan ini dapat diketahui seberapa besar selisih antara Head teoritis dengan Head aktual, adanya selisih ini di karenakan pada pengoperasiannya hanya di butuhkan Head sebesar 55,36 m dengan rata-rata $77,9 \mathrm{~m}^{3} / \mathrm{h}$. Kerugian akibat adanya gesekan, elbow,valve,dan tee line pada bagian suction adalah sebesar $8,5 \mathrm{~m}$ sedangkan pada bagian discharge adalah sebesar 23,3 m.

Kecepatan aliran pada Suction adalah $1,187 \mathrm{~m} / \mathrm{s}$, dan Kecepatan aliran pada Discharge adalah $2,65 \mathrm{~m} / \mathrm{s}$.
Efisiensi desain pompa adalah sebesar $72,5 \%$ sedangkan efisiensi aktual pompa adalah sebesar 49,94\%.

\section{REFERENSI}

[1] N. Erni and B. Wijaya, Usulan Penerapan Teori Markov Dalam PengambilanKeputusan Perawatan Tahunan Pada PT . Pupuk Kujang, pp. 56-63. 2011.

[2] J. Delly, Pengaruh temperatur terhadap terjadinya kavitasi pada sudu pompa sentrifugal, Ilm. Tek. mesin, vol. 1, no. 1, pp. 21-28. 2009.

[3] S. Hariady, Analisa Kerusakan Pompa Sentrifugal 53-101c Wtu Sungai Gerong PT . Pertamina Ru Iii Plaju, vol. 2, no. 1, pp. 29-42. 2014.

[4] alkonusa, 2016. Pengertian Pompa Sentrifugal, [Online] (Updated 10 Febuari 2016) Tersedia di: http://www.alkonusa.com/news/pen gertian-pompa-sentrifugal-danprinsip-kerjanyal.

[5] I. N. Gusniar, Optimalisasi Sistem Perawatan Pompa Sentrifugal Di Unit Utility PT.ABC," Ilm. solusi. 2014.

[6] W. D. Putro, Pengujian Kinerja Pompa Sentrifugal Menggunakan Kontrol Inventer, Ilm. semesta Tek., vol. 13, no. 1, pp. 21-30, 2010.

[7] A. Rahman and M. Zakinura, "Analisa low performance pompa sentrifugal single stage double souction radially split tipe bb.2," Politek. NEGERI JAKARTA, pp. 496-501.

[8] E. Nugroho, A. Sunaryunanto, Helmizar, A. Nuramal, and A. Suandi, "Analisa Performance Pompa Sentrifugal Item 6p-4021-J Yang Dipengaruhi Kondisi Strainer Terhadap Efisiensi Kerja Yang Dihasilkan," Ilm. Tek. Mesin, vol. 3, no. 2. 2019. 